Original article

\title{
The effect of 2 mMol glutamine supplementation on HSP70 and TNF- $\alpha$ release by LPS stimulated blood from healthy children
}

\author{
L.V. Marino ${ }^{\mathrm{a},}{ }^{*}$, N. Pathan ${ }^{\mathrm{b}}$, R. Meyer ${ }^{\mathrm{c}}$, V.J. Wright ${ }^{\mathrm{a}}$, P. Habibi ${ }^{\mathrm{a}}$ \\ a Department of Paediatrics, Imperial College, London, UK \\ b Department of Paediatrics, School of Clinical Medicine, Cambridge University, UK \\ ${ }^{c}$ Department of Gastroenterology, Great Ormond Street Hospital for Sick Children, London, UK
}

\section{A R T I C L E I N F O}

\section{Article history:}

Received 4 June 2014

Accepted 16 December 2014

\section{Keywords:}

Paediatrics

Glutamine

HSP70

Sepsis

Inflammatory mediators

Critical illness

\begin{abstract}
S U M M A R Y
Objective: Glutamine has been shown to promote heat shock protein 70 (HSP70) release both within experimental in vitro models of sepsis $(2-10 \mathrm{mM})$ and in adults post trauma $(0.5 \mathrm{~g} / \mathrm{kg})$, although the efficacy varies and is dependent on the model used. The effect of glutamine supplementation on HSP70 release in children is less clear. Therefore, the aim of this study was to investigate the effect of $2 \mathrm{mM}$ glutamine added to incubation media on HSP70 and inflammatory mediator release in an in vitro model of paediatric sepsis using whole blood from healthy paediatric volunteers.

Methods: An in vitro whole blood endotoxin stimulation model using $1 \mu \mathrm{g} / \mathrm{ml}$ lipopolysaccharide (LPS) over a $24 \mathrm{~h}$ time period was used to investigate the effects of $2 \mathrm{mM}$ glutamine on HSP70 and inflammatory mediator release in healthy children.

Results: The addition of $2 \mathrm{mM}$ glutamine to the incubation media significantly increased HSP70 release over time $(p<0.05)$. This was associated with an early pro-inflammatory effect on TNF- $\alpha$ release at $4 \mathrm{~h}(\mathrm{p}<0.005)$ which was not seen at $24 \mathrm{~h}$. There was a non significant trend towards higher levels of IL6 and IL-10 following the addition of $2 \mathrm{mM}$ glutamine, which appears to differ from the response reported in adult and animal models.

Conclusion: Glutamine supplementation of incubation media promotes HSP70 and early TNF- $\alpha$ release in an in vitro model using blood samples from healthy children.
\end{abstract}

(C) 2014 Elsevier Ltd and European Society for Clinical Nutrition and Metabolism. All rights reserved.

\section{What is known:}

- The addition of glutamine to incubation media promotes HSP70 release in in vitro experimental models of sepsis.

- During times of infection, HSP70 release signals via cell surface ligands TLR2 and 4 activating inflammatory pathway of $\mathrm{NF}_{-\mathrm{K}} \mathrm{B}$ promoting the release of inflammatory mediators.

\section{What this study adds:}

- The addition of $2 \mathrm{mM}$ glutamine to incubation media in a paediatric in vitro model of sepsis significantly increased HSP70 levels over time.

- The addition of $2 \mathrm{mM}$ glutamine to incubation media appeared to promote an early pro-inflammatory response in a paediatric model of sepsis.

\section{Introduction}

HSP70 forms part of the cellular response to stress [1]. Levels of extracellular HSP70 are increased, in response to infection, forming a network of molecules discharged by stressed or damaged cells [2,3]. HSP70 has powerful immunoregulatory effects [4-7], providing cellular protection [8] preventing apoptosis and cell death [9-13]. Under normal circumstances HSP70 is detectable in

\footnotetext{
* Corresponding author. Department of Nutrition and Dietetics, University Hospital Southampton NHS Foundation Trust, Southampton S016 6YD, UK. Tel.: +44 (0) 2380796072.

E-mail address: luise.marino@uhs.nhs.uk (L.V. Marino).
} 
plasma of healthy individuals (who have no evidence of inflammation), suggesting that during times of homeostasis, HSP70 does not promote an inflammatory response and its immunoregulatory/ inflammatory functions are tightly controlled [3]. However, during times of stress HSP70 is able to interact with antigen presenting cells (APC's) and activate both innate as well as adaptive immunity. The type of response elicited depends on whether HSP70 is within or external to the cell, the particular cell surface receptor sites it binds to [14] and the type of $\mathrm{T}$ cells stimulated. In experimental model of sepsis, in vitro cell culture models HSP70 has been shown to signal via the Toll like receptors (TLR) 2/4-MyD88-nuclear factor kappa $\mathrm{B}(\mathrm{NF}-\kappa \mathrm{B})$ pathway promoting the release of inflammatory mediators [15] influencing the mix of cytokines released [3]. As the stress response resolves, HSP70 acts to dampen down the inflammatory and immunoregulatory response, restoring cellular homeostasis [16,17].

As such the effects of HSP70 appear to be dependent of the model used (e.g. cell culture, animal, human). A recent analysis considering the effect of HSP70 in animal models compared to humans indicate that whilst HSP70 confers an almost entirely protective effect in animals (97.1\%) the same may not be true in humans, with only a $50 \%$ protective effect demonstrated [1]. Therefore the clinical benefit of HSP70 upregulation during times of stress remains unclear, especially as both low and high levels in children and adults are associated with increased risk in children and adults mortality and infection risk $[1,18]$. In adults following trauma HSP70 levels $\leq 15 \mathrm{ng} / \mathrm{ml}$ is associated with increased mortality [19], conversely, levels $\geq 60 \mathrm{ng} / \mathrm{ml}$ is associated with increased mortality in traumatic brain injury [20] and severe sepsis in adults [21] and children [22]. Our own work in children with acute meningococcal disease, found significantly higher levels of HSP70 in the acute phase of illness, although this were not associated with increased mortality [23].

Glutamine, as a modulator of the heat shock response [24] is well described in experimental models of sepsis [25] and in adults following trauma [26]. Glutamine exerts a complex regulatory activity with respect to the activation of intracellular signalling pathways associated with inflammation and can influence the milieu of inflammatory mediator release in response to stress independently of HSP70 [27,28].

We have previously shown that glutamine depletion occurs in critically ill children and is correlated with length of stay and illness severity scores [23]. There is, however, limited information regarding the effect of glutamine supplementation on the HSP70 and inflammatory mediator release in children [29]. As such we sought to investigate the in vitro effects of endotoxin and glutamine on HSP70 release and its association with markers of inflammatory response, using an in vitro whole blood model in healthy paediatric volunteers. As HSP70 is produced by a large variety of cells including granulocytes and peripheral mononuclear cells [3] we chose to use an in vitro whole blood endotoxin stimulation model. Endotoxin has been used extensively to understand the pathophysiological response to sepsis/stress as well as for the study of cytokine [30] and HSP70 release [31], providing further insight into the host response [32].

The aim of this study was to investigate the effect of the addition of $2 \mathrm{mM}$ glutamine to incubation media on HSP70 and inflammatory mediator release in an in vitro model of paediatric sepsis.

\section{Materials and methods}

This study was approved by the St Mary's Hospital Imperial College Foundation Trust (reference number EC3262). After obtaining informed parental consent, 25 healthy children were prospectively enrolled from a general paediatric outpatient clinic.
Heparinised whole blood was diluted 1:1 with glutamine free RPMI (Sigma Aldrich), stimulated with \pm LPS $(1 \mu \mathrm{g} / \mathrm{ml})$ in duplicate, and incubated at $37^{\circ} \mathrm{C}, 5 \% \mathrm{CO}_{2}$. After $2 \mathrm{~h}$ of culture, $2 \mathrm{mM}$ glutamine was added to half the conditions and incubated for another $2 \mathrm{~h}$ and for a further $22 \mathrm{~h}$. At each time point ( $4 \mathrm{~h}$ and $24 \mathrm{~h}$ ) supernatant was removed, centrifuged for $10 \mathrm{~min}$ at $1200 \mathrm{~g}$ and immediately stored at $-80^{\circ} \mathrm{C}$. HSP70 and inflammatory mediators were measured as per manufacturer's instructions using High Sensitivity HSP70 (HSP72) ELISA (Enzo Life Sciences CA; USA) and MSD Human proinflammatory - 3 II ultra sensitive ELISA (Meso Scale; MY; USA) measuring inflammatory mediators IL-6, TNF- $\alpha$ and IL-10. As plasma from whole blood in vitro model was used, we were not able to discriminate between the source (e.g. granulocytes, lymphocytes or peripheral mononuclear cells) and subsequent role of the HSP70 released from the in vitro cell mix.

Statistical analysis of clinical variables, HSP70 and cytokine data was completed using statistical analysis package Graphpad Prism 4.0 for Windows (Graphpad Software, San Diego, CA) and Statistical Package for Social Sciences 19.0 (SPSS: An IBM Company, Chicago, IL).

\section{Results}

\subsection{Effect of $2 \mathrm{mM}$ glutamine on HSP70 release in endotoxin stimulated whole blood from healthy paediatric volunteers}

In children, the addition of $2 \mathrm{mM}$ glutamine to incubation media significantly upregulated HSP70 release at $24 \mathrm{~h}$ in endotoxin stimulated whole blood $(\mathrm{p}<0.005)$ in comparison to conditions with no glutamine (Fig. 1). In unstimulated blood, the release of HPS70 was significantly upregulated at $24 \mathrm{~h}$ in conditions with/ without glutamine compared to those at $4 \mathrm{~h}(\mathrm{p}<0.005)$ (Fig. 1).

The addition of $2 \mathrm{mM}$ glutamine to incubation media with endotoxin significantly stimulated the release of TNF- $\alpha$ at $4 \mathrm{~h}(\mathrm{p}<0.05)$ but not at $24 \mathrm{~h}$ (Fig. 2). A similar effect was seen with IL-6, although this was not significant (Fig. 3). $2 \mathrm{mM}$ glutamine appeared to have no effect on the release of IL-10 (Fig. 4). There was a positive correlations between HSP70 and IL-6 $(\mathrm{n}=25, \mathrm{r}=0.61$, $\mathrm{p}=0.004)$ and TNF- $\alpha(\mathrm{n}=25, \mathrm{r}=0.61, \mathrm{p}=0.005)$ at $4 \mathrm{~h}$ following the addition of $2 \mathrm{mM}$ glutamine to incubation media (Fig. $5 \mathrm{a}$ and $\mathrm{b}$ ) but there was no relationship between HSP70 and IL-10 ( $\mathrm{n}=25$, $\mathrm{r}=0.191, \mathrm{p}=0.382$ ).

\section{Discussion}

In an in vitro model of paediatric sepsis the addition of $2 \mathrm{mM}$ glutamine to incubation media significantly increased HSP70 release at $24 \mathrm{~h}$, concurring with other models of experimental sepsis [25,33] and critically ill adults [26]. However, in addition, to this we also found there was a significant release of HSP70 in unstimulated whole blood control wells with and without glutamine. The significant increase in HSP70 levels appears to be a physiological response to the experimental conditions, and has previously been described in vitro and in vivo studies [25,34-36] and is unlikely to be due to endotoxin contamination given that inflammatory mediator levels were low at each time point in control wells. The addition of $2 \mathrm{mM}$ glutamine to incubation media in endotoxin stimulated blood from paediatric volunteers significantly increased the release of TNF- $\alpha$ at $4 \mathrm{~h}$, although at $24 \mathrm{~h}$ the release of TNF- $\alpha$ in endotoxin stimulated blood was not significantly different. There was a similar but non significant trend for IL6 release after the addition of $2 \mathrm{mM}$ glutamine to incubation media. However, The addition of $2 \mathrm{mM}$ glutamine had no discernible effect on IL-10 at 4 or $24 \mathrm{~h}$ following endotoxin stimulation though it may be that dosage greater than $2 \mathrm{mM}$ glutamine is required to significantly influence the release of inflammatory mediators $[37,38]$. 


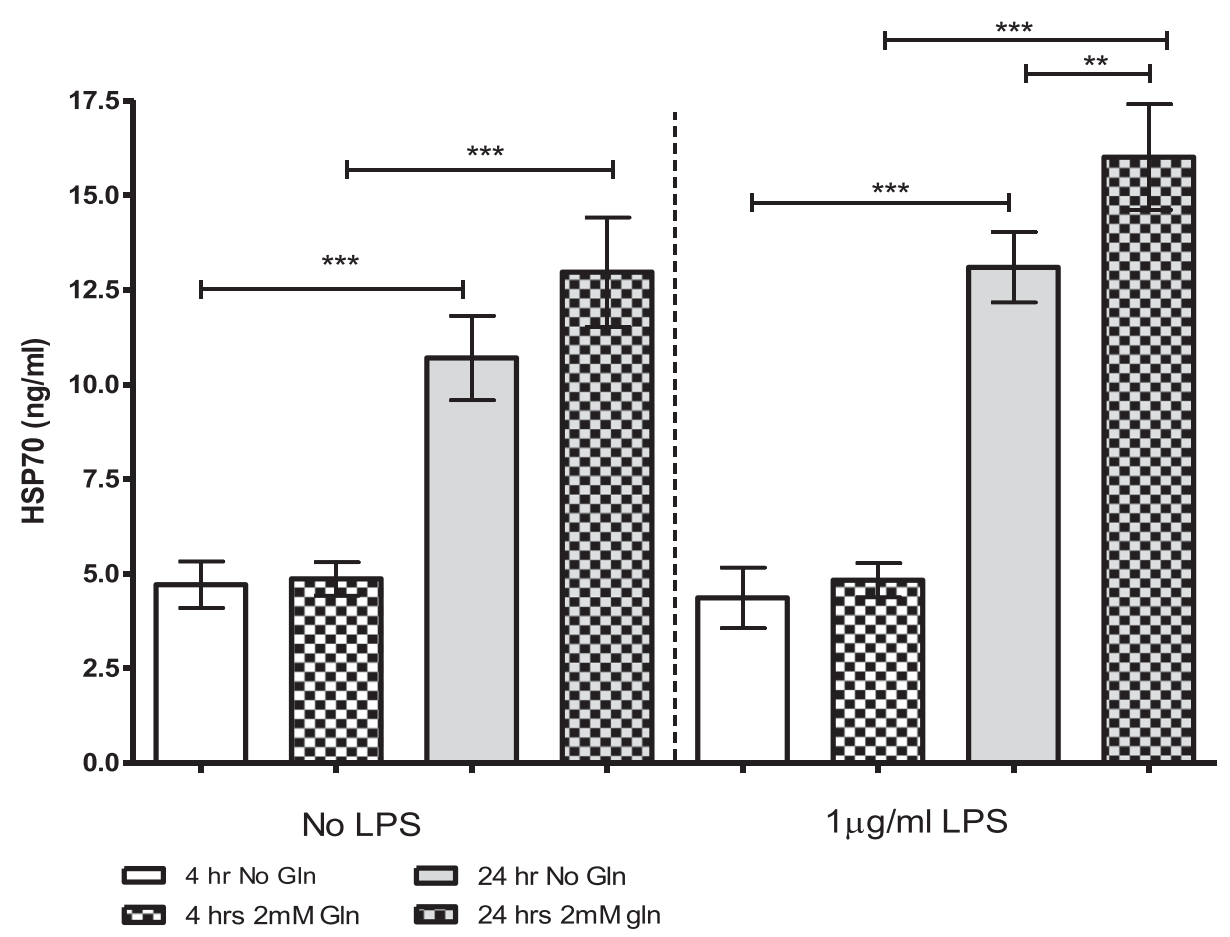

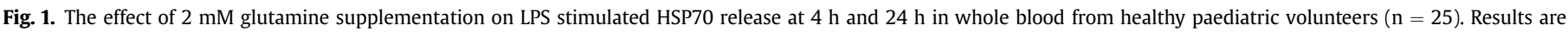
expressed as mean; \pm SEM. Glutamine = glutamine, LPS $=$ endotoxin $^{* *} \mathrm{p}<0.005,{ }^{* * *} \mathrm{p}<0.0005$.

The putative role of extracellular HSP70 during times of stress in children has yet to clearly defined, making it challenging to interpret our results. It has been postulated that constitutive levels of extracellular HSP70 in vivo help maintain immune homeostasis through $\mathrm{T}$ regulatory cell control. During times of stress high levels of HSP70 are released at sites of infection or tissue damage resulting in a loss of $\mathrm{T}$ regulatory cell control contributing to a pro-inflammatory response, which reflects the response seen in our in vitro model. As the stress response resolves and HSP70 levels decline $\mathrm{T}$ regulatory cell function is restored with a resolution of the inflammatory response and return to homeostasis $[39,40]$.

HSP70 also appears to influence the mix of cytokines released, which is dependent on the model used, for example an in vitro

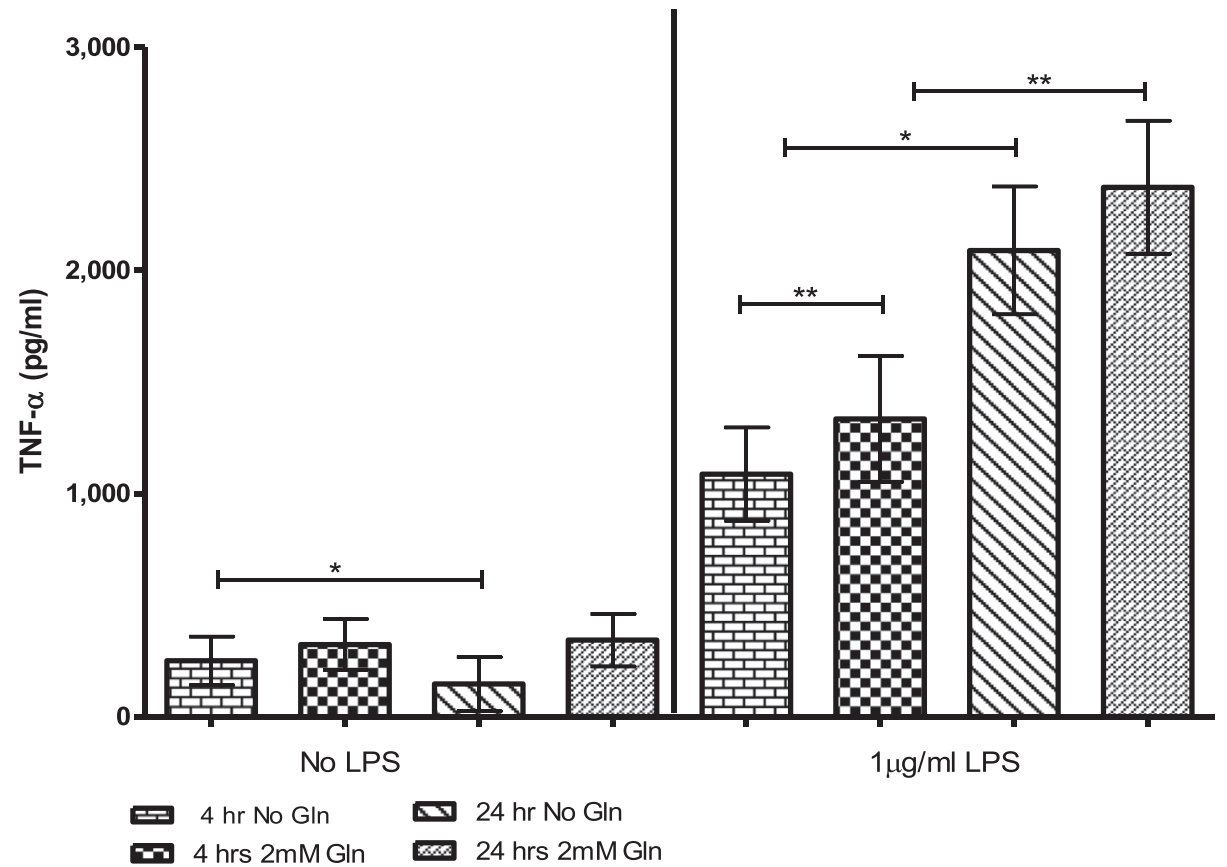

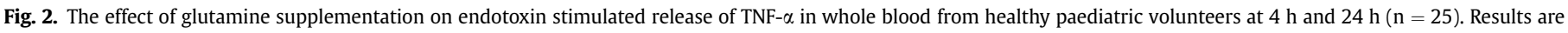
expressed as mean; \pm SEM. Glutamine $=$ glutamine, LPS $=$ endotoxin ${ }^{*} \mathrm{p}<0.05,{ }^{* *} \mathrm{p}<0.005$ 


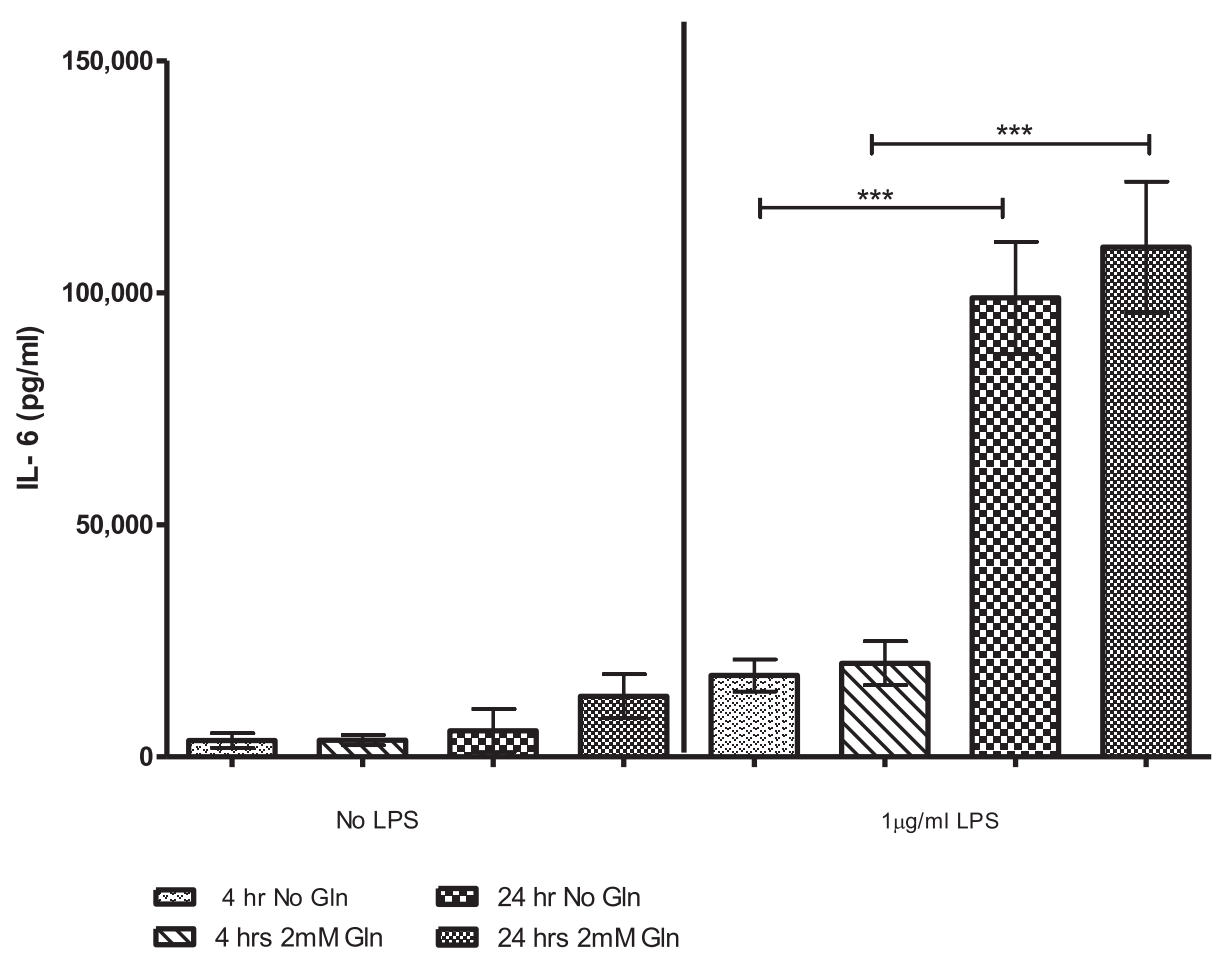

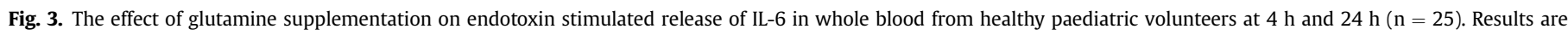
expressed as mean; \pm SEM. Glutamine $=$ glutamine, LPS $=$ endotoxin ${ }^{* * *} \mathrm{p}<0.0005$.

model of sepsis model using, either lipoteichoic acid or LPS, shows that pre-treatment of human neutrophils with recombinant HSP70 prior to the administration of endotoxin attenuates the release of TNF- $\alpha$ [41]. This is corroborated in other in vitro animal models where the use of recombinant HSP70 provides a similar anti- inflammatory mode of action by inhibiting $\mathrm{C} / \mathrm{EBP} \beta$ and $\mathrm{C} / \mathrm{EPB} \delta$ transcription factors from signalling via TLR2-ERK-STAT2-1L10 pathway, attenuating the release of pro-inflammatory mediators [42]. Converse to this, when healthy subjects were inoculated with endotoxin, levels of HSP70 and proinflammatory mediators

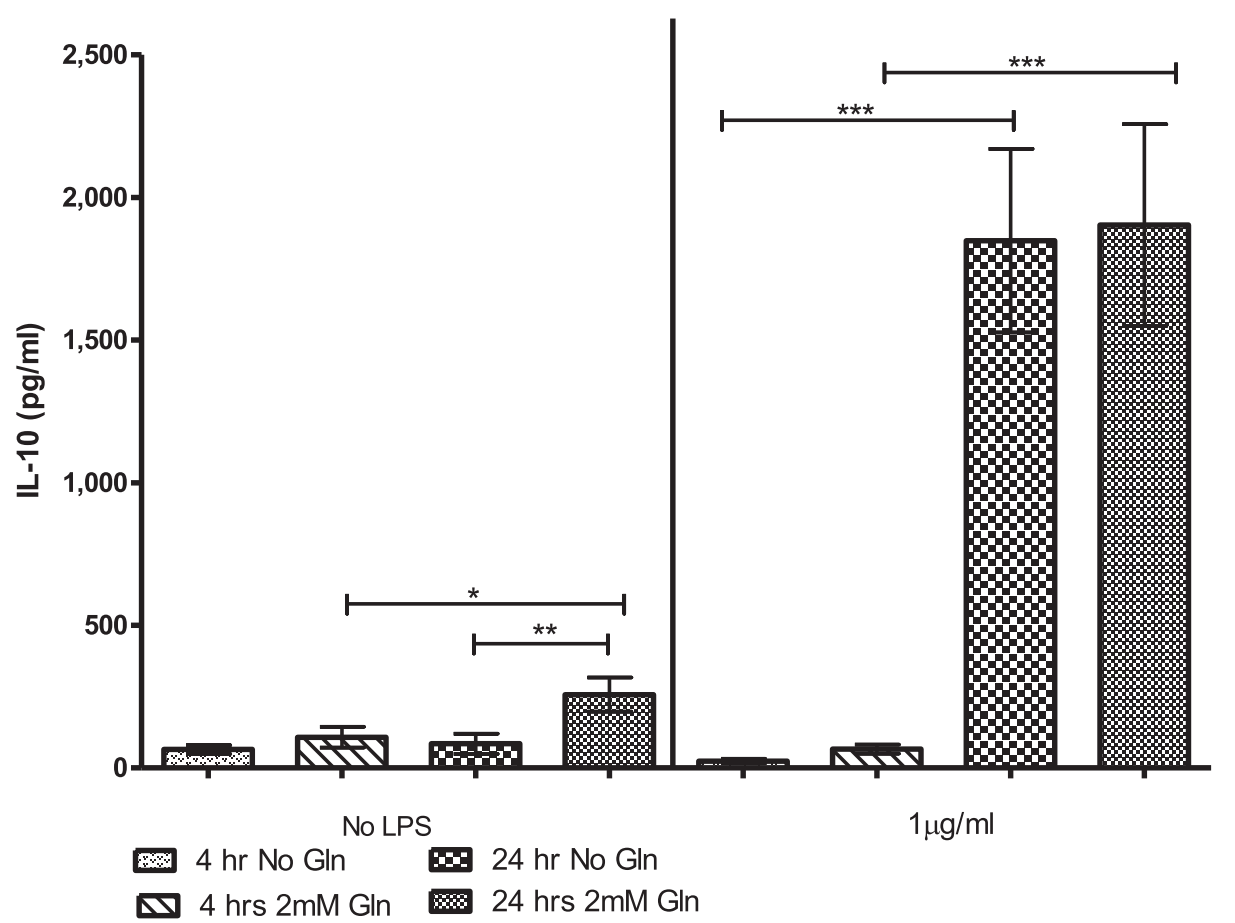

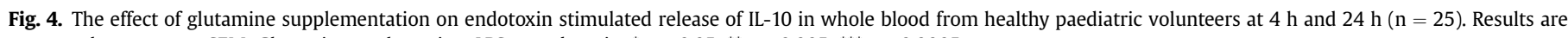
expressed as mean; \pm SEM. Glutamine = glutamine, LPS $=$ endotoxin. ${ }^{*} \mathrm{p}=0.05,{ }^{* *} \mathrm{p}<0.005,{ }^{* * *} \mathrm{p}<0.0005$. 

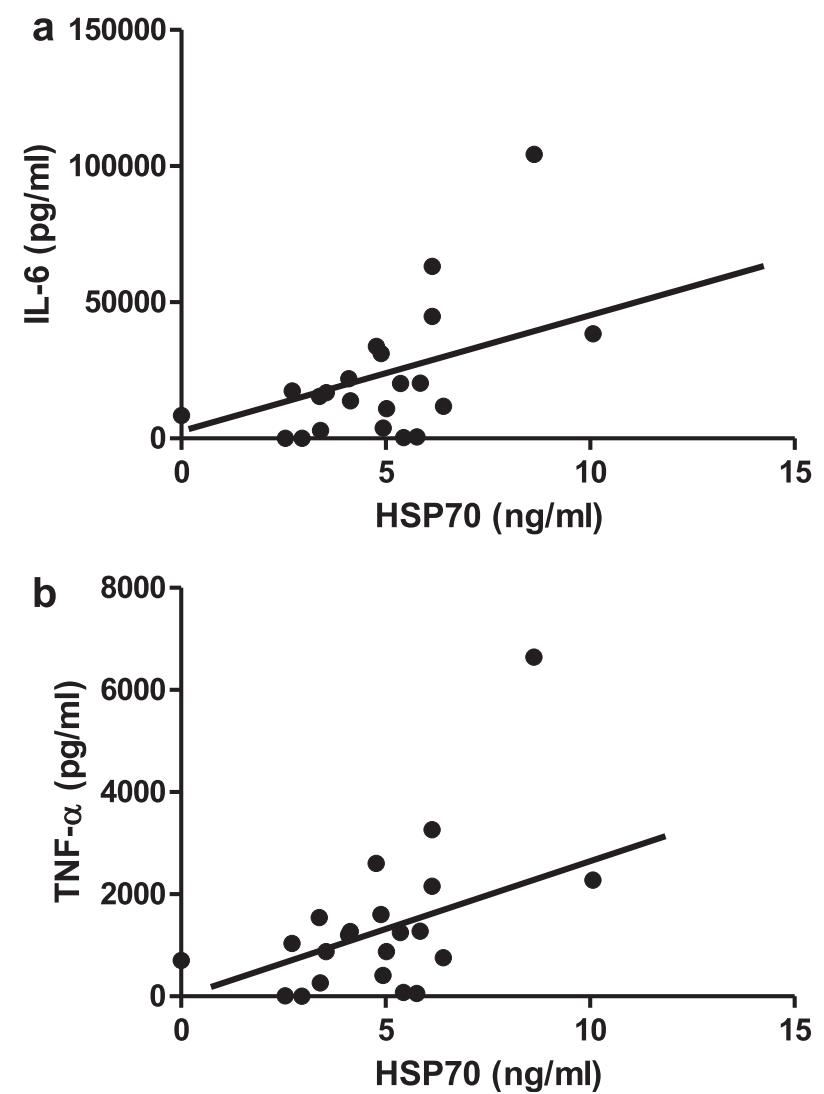

Fig. 5. a) Graphical representation (scatter plot) correlations between the effect of glutamine supplementation on endotoxin stimulated release of IL-6 in whole blood from healthy paediatric volunteers at $4 \mathrm{~h}(\mathrm{n}=25, \mathrm{r}=0.61, \mathrm{p}=0.004)$. b) Graphical representation (scatter plot) correlations between the effect of glutamine supplementation on endotoxin stimulated release of TNF- $\alpha$ in whole blood from healthy paediatric volunteers at $4 \mathrm{~h}(\mathrm{n}=25, \mathrm{r}=0.61, \mathrm{p}=0.005)$

subsequently increased although the causality regarding the pleiotropic effect of HSP70 was not established [31].

In our study the addition of $2 \mathrm{mM}$ glutamine to incubation media appeared to promote the release of pro-inflammatory mediators [43], which could be reflective of experimental conditions, levels of extracellular HSP70 release or glutamine levels within the in vitro model. The cellular response to infection is a complex process co-ordinated by a wide range of intra- and extracellular mediators. Within this dynamic, glutamine and HSP70 influence and are influenced by, the mix of inflammatory mediators, activating protective cellular defence mechanisms [44], and a challenge for the future is to elucidate whether there is any clinical relevance of this in critically ill children.

Glutamine supplementation in children has yielded conflicting results. In studies of glutamine supplementation in pre-term infants [45-50], infants with gastrointestinal disease and surgery [51,52], children with burns [53,54] and malnutrition [55-57], little or no benefit on survival, late onset sepsis or duration of hospital stay have been described [18]. In addition recent evidence indicates that either hypo-glutamine $<430 \mu \mathrm{mol} / \mathrm{L}$ [58] or hyper-glutamine levels $>930 \mu \mathrm{mol} / \mathrm{L}$ are associated with increased mortality $[59,60]$. The mechanism for the effect of supra physiological glutamine levels on HSP70 release and inflammatory mediators in critical illness is not known. However, an in vitro model of human skeletal muscle linked supraphysiological levels of glutamine to respiratory uncoupling and energy wasting within the mitochondria which was associated with cell death [61]. In addition, Krajcova et al. have suggested the hypoglutaminaemia seen during critical illness may be a protective mechanism. They show that supra physiological levels of glutamine decrease the efficiency of the mitochondrial respiratory chain contributing to the bioenergetics failure of the mitochondria (a feature of critical illness), where engorged mitochondria are not able to meet adenosine tri phosphate demands of tissues, resulting in cell death [61]. As such the hypoglutaminaemia described by us [23] and others during critical illness [62], may be a protective mechanism decreasing mitochondrial size allowing for restoration and repair during the recovery phase [61].

Furthermore, it may also be the increased mortality seen in these studies may be as a result of the metabolic decompensation associated with sepsis/septic shock and multiorgan failure rather than the effect of glutamine per se [59,60]. The effective modulation and management of the inflammatory response to infection remains elusive, as complete abrogation of inflammation and or over stimulation results in increased mortality [63].

Our results suggest that the addition of $2 \mathrm{mM}$ glutamine to incubation media using an in vitro endotoxin model from whole blood of healthy children, may promote increased levels of TNF- $\alpha$, and mediated via HSP70 release, although the clinical significance of this is not known. Since the results from Heyland and Dhaliwal [64] describing the increased risk of mortality following the use of glutamine in sepsis, supplementation is no longer recommended [65]. Furthermore, the effect of glutamine supplementation has not been elucidated in critically ill children and so its use cannot be recommended in immune competent children [18]. Further work is required to understand what the role of glutamine is in critically ill children.

The conclusions from our work should be regarded with some caution owing to certain limitations of the study, which include the investigation of only one dose of glutamine $(2 \mathrm{mM})$ that significantly upregulated HSP70 release in paediatric endotoxin stimulation models. The effect of $2 \mathrm{mM}$ glutamine on the release of inflammatory mediators was less clear. It may be that a large dose of glutamine ( $\geq 2 \mathrm{mM}$ ) is required in the paediatric models to better understand the effect of glutamine mediated HSP70 release and subsequent milieu of inflammatory mediators. Although a range of pro- and anti-inflammatory mediators were selected for study based on previous work in meningococcal disease, it was not possible to examine all those of interest within a single validated multiplex plate as we were limited on blood volume available from paediatric samples. Another limitation of our in vitro models was the lack of discrimination between live and dead cells, which prevented the source of HSP70 release (e.g. passive release or as a result of necrosis) from being determined.

\section{Conclusion}

These results would suggest that the addition of $2 \mathrm{mM}$ glutamine to incubation media promotes HSP70 release in an in vitro endotoxin stimulation model in children. The results from this work highlight the need to explore the relationships of glutamine, HSP70 and inflammatory mediators further, particularly given the conflicting reports of benefit of glutamine during critical illness. Given the current paucity of evidence regarding the efficacy of glutamine supplementation during paediatric critical illness and sepsis it should not be given until the effects of supplementation on the inflammatory response are better understood.

\section{Conflict of interest}

The authors declare no conflict of interest. 


\section{References}

[1] Briassoulis G, Briassouli E, Fitrolaki DM, Plati I, Apostolou K, Tavladaki T, et al. Heat shock protein 72 expressing stress in sepsis: unbridgeable gap between animal and human studies-a hypothetical "comparative" study. Biomed Res Int 2014;2014:101023.

[2] Henderson B, Calderwood SK, Coates AR, Cohen I, van Eden W, Lehner T, et al. Caught with their PAMPs down? the extracellular signalling actions of molecular chaperones are not due to microbial contaminants. Cell Stress Chaperones 2010 Mar;15(2):123-41.

[3] Pockley AG, Muthana M, Calderwood SK. The dual immunoregulatory roles of stress proteins. Trends Biochem Sci 2008 Feb;33(2):71-9.

[4] Matzinger P. An innate sense of danger. Semin Immunol 1998 Oct;10(5); 399-415.

[5] Matzinger P. The danger model: a renewed sense of self. Science 2002 Apr 12;296(5566):301-5.

[6] Gallucci S, Matzinger P. Danger signals: SOS to the immune system. Curr Opin Immunol 2001 Feb;13(1):114-9.

[7] Vega VL, Rodriguez-Silva M, Frey T, Gehrmann M, Diaz JC, Steinem C, et al. Hsp70 translocates into the plasma membrane after stress and is released into the extracellular environment in a membrane-associated form that activates macrophages. J Immunol 2008 Mar 15;180(6):4299-307.

[8] Henderson B, Pockley AG. Molecular chaperones and protein-folding catalysts as intercellular signaling regulators in immunity and inflammation. J Leukoc Biol 2010 Sep;88(3):445-62.

[9] De Maio A. Heat shock proteins: facts, thoughts, and dreams. Shock 1999 Jan;11(1):1-12.

[10] Ribeiro SP, Villar J, Downey GP, Edelson JD, Slutsky AS. Effects of the stress response in septic rats and LPS-stimulated alveolar macrophages: evidence for TNF-alpha posttranslational regulation. Am J Respir Crit Care Med 1996 Dec;154(6 Pt 1):1843-50.

[11] Ribeiro SP, Villar J, Slutsky AS. Induction of the stress response to prevent organ injury. New Horiz 1995 May;3(2):301-11.

[12] Villar J, Ribeiro SP, Mullen JB, Kuliszewski M, Post M, Slutsky AS. Induction of the heat shock response reduces mortality rate and organ damage in a sepsisinduced acute lung injury model. Crit Care Med 1994 Jun;22(6):914-21.

[13] Ribeiro SP, Villar J, Downey GP, Edelson JD, Slutsky AS. Sodium arsenite induces heat shock protein-72 kilodalton expression in the lungs and protects rats against sepsis. Crit Care Med 1994 Jun;22(6):922-9.

[14] Asea A. Mechanisms of HSP72 release. J Biosci 2007 Apr;32(3):579-84.

[15] Dokladny K, Lobb R, Wharton W, Ma TY, Moseley PL. LPS-induced cytokine levels are repressed by elevated expression of HSP70 in rats: possible role of NF-kappaB. Cell Stress Chaperones 2010 Mar;15(2):153-63.

[16] Binder RJ, Vatner R, Srivastava P. The heat-shock protein receptors: some answers and more questions. Tissue Antigens 2004 Oct;64(4):442-51.

[17] van Eden W, Spiering R, Broere F, van der Zee R. A case of mistaken identity: HSPs are no DAMPs but DAMPERs. Cell Stress Chaperones 2012;17 (3):281-92.

[18] Briassouli E, Briassoulis G. Glutamine randomized studies in early life: the unsolved riddle of experimental and clinical studies. Clin Dev Immunol 2012;2012:749189.

[19] Pittet JF, Lee H, Morabito D, Howard MB, Welch WJ, Mackersie RC. Serum levels of Hsp 72 measured early after trauma correlate with survival. J Trauma 2002 Apr;52(4):611-7. discussion 7.

[20] da Rocha AB, Zanoni C, de Freitas GR, Andre C, Himelfarb S, Schneider RF, et al. Serum Hsp70 as an early predictor of fatal outcome after severe traumatic brain injury in males. J Neurotrauma 2005 Sep;22(9):966-77.

[21] Gelain DP, de Bittencourt Pasquali MA, Comim MC, Grunwald MS, Ritter C, Tomasi CD, et al. Serum heat shock protein 70 levels, oxidant status, and mortality in sepsis. Shock 2011 May;35(5):466-70.

[22] Wheeler DS, Fisher Jr LE, Catravas JD, Jacobs BR, Carcillo JA, Wong HR. Extracellular hsp70 levels in children with septic shock. Pediatr Crit Care Med 2005 May;6(3):308-11.

[23] Marino LV, Pathan N, Meyer R, Wright V, Habibi P. Glutamine depletion and heat shock protein 70 (HSP70) in children with meningococcal disease. Clin Nutr 2014;33(5):915-21.

[24] Wischmeyer PE. Glutamine: the first clinically relevant pharmacological regulator of heat shock protein expression? Curr Opin Clin Nutr Metab Care 2006 May;9(3):201-6.

[25] Singleton KD, Serkova N, Beckey VE, Wischmeyer PE. Glutamine attenuates lung injury and improves survival after sepsis: role of enhanced heat shock protein expression. Crit Care Med 2005 Jun;33(6):1206-13.

[26] Ziegler TR, Ogden LG, Singleton KD, Luo M, Fernandez-Estivariz C, Griffith DP, et al. Parenteral glutamine increases serum heat shock protein 70 in critically ill patients. Intensive Care Med 2005 Aug;31(8):1079-86.

[27] Rhoads JM, Argenzio RA, Chen W, Rippe RA, Westwick JK, Cox AD, et al. Lglutamine stimulates intestinal cell proliferation and activates mitogenactivated protein kinases. Am J Phys 1997 May;272(5 Pt 1):G943-53.

[28] Brasse-Lagnel C, Lavoinne A, Husson A. Control of mammalian gene expression by amino acids, especially glutamine. FEBS J 2009 Apr;276(7):1826-44.

[29] Skillman HE, Wischmeyer PE. Nutrition therapy in critically ill infants and children. JPEN J Parenter Enter Nutr 2008 Sep-Oct;32(5):520-34.

[30] Stallion A, Kou TD, Latifi SQ Miller KA, Dahms BB, Dudgeon DL, et al. Ischemia/ reperfusion: a clinically relevant model of intestinal injury yielding systemic inflammation. J Pediatr Surg 2005 Mar;40(3):470-7.
[31] Andreasen AS, Pedersen-Skovsgaard T, Mortensen OH, van Hall G, Moseley PL, Pedersen BK. The effect of glutamine infusion on the inflammatory response and HSP70 during human experimental endotoxaemia. Crit Care 2009;13(1): R7.

[32] Chen D, Pan J, Du B, Sun D. Induction of the heat shock response in vivo inhibits NF-kappaB activity and protects murine liver from endotoxemiainduced injury. J Clin Immunol 2005 Sep;25(5):452-61.

[33] Ropeleski MJ, Riehm J, Baer KA, Musch MW, Chang EB. Anti-apoptotic effects of L-glutamine-mediated transcriptional modulation of the heat shock protein 72 during heat shock. Gastroenterology 2005 Jul;129(1):170-84.

[34] Singleton KD, Serkova N, Banerjee A, Meng X, Gamboni-Robertson F, Wischmeyer PE. Glutamine attenuates endotoxin-induced lung metabolic dysfunction: potential role of enhanced heat shock protein 70. Nutrition 2005 Feb;21(2):214-23.

[35] Mazloomi E, Jazani NH, Sohrabpour M, Ilkhanizadeh B, Shahabi S. Synergistic effects of glutamine and ciprofloxacin in reduction of Pseudomonas aeruginosa-induced septic shock severity. Int Immunopharmacol 2011 Dec;11(12):2214-9.

[36] Singleton KD, Wischmeyer PE. Glutamine's protection against sepsis and lung injury is dependent on heat shock protein 70 expression. Am J Physiol Regul Integr Comp Physiol 2007 May;292(5):R1839-45.

[37] Singleton KD, Beckey VE, Wischmeyer PE. Glutamine prevents activation of NF-kappaB and stress kinase pathways, attenuates inflammatory cytokine release, and prevents acute respiratory distress syndrome (ARDS) following sepsis. Shock 2005 Dec;24(6):583-9.

[38] Garrett-Cox RG, Stefanutti G, Booth C, Klein NJ, Pierro A, Eaton S. Glutamine decreases inflammation in infant rat endotoxemia. J Pediatr Surg 2009 Mar;44(3):523-9.

[39] Albani S, Koffeman EC, Prakken B. Induction of immune tolerance in the treatment of rheumatoid arthritis. Nat Rev Rheumatol 2011 May;7(5): $272-81$.

[40] Fischer B, Elias D, Bretzel RG, Linn T. Immunomodulation with heat shock protein DiaPep277 to preserve beta cell function in type 1 diabetes - an update. Expert Opin Biol Ther 2010 Feb;10(2):265-72.

[41] Vinokurov M, Ostrov V, Yurinskaya M, Garbuz D, Murashev A, Antonova O et al. Recombinant human Hsp70 protects against lipoteichoic acid-induced inflammation manifestations at the cellular and organismal levels. Cell Stress Chaperones 2012 Jan;17(1):89-101.

[42] Borges TJ, Lopes RL, Pinho NG, Machado FD, Souza AP, Bonorino C. Extracellular Hsp70 inhibits pro-inflammatory cytokine production by IL-10 driven down-regulation of C/EBPbeta and C/EBPdelta. Int J Hyperthermia 2013 Aug;29(5):455-63.

[43] Singleton KD, Wischmeyer PE. Glutamine attenuates inflammation and NFkappaB activation via Cullin-1 deneddylation. Biochem Biophys Res Commun 2008 Aug 29;373(3):445-9.

[44] Jang HJ, Kwak JH, Cho EY, We YM, Lee YH, Kim SC, et al. Glutamine induces heat-shock protein-70 and glutathione expression and attenuates ischemic damage in rat islets. Transplant Proc 2008 Oct;40(8):2581-4.

[45] Tubman TR, Thompson SW, McGuire W. Glutamine supplementation to prevent morbidity and mortality in preterm infants. Cochrane Database Syst Rev 2008;(1):CD001457.

[46] van den Berg A, van Elburg RM, Westerbeek EA, Twisk JW, Fetter WP. Glutamine-enriched enteral nutrition in very-low-birth-weight infants and effects on feeding tolerance and infectious morbidity: a randomized controlled trial. Am J Clin Nutr 2005 Jun;81(6):1397-404.

[47] Thompson SW, McClure BG, Tubman TR. A randomized, controlled trial of parenteral glutamine in ill, very low birth-weight neonates. J Pediatr Gastroenterol Nutr 2003 Nov;37(5):550-3.

[48] Dallas MJ, Bowling D, Roig JC, Auestad N, Neu J. Enteral glutamine supplementation for very-low-birth-weight infants decreases hospital costs. JPEN J Parenter Enter Nutr 1998 Nov-Dec;22(6):352-6.

[49] Darmaun D, Roig JC, Auestad N, Sager BK, Neu J. Glutamine metabolism in very low birth weight infants. Pediatr Res 1997 Mar;41(3):391-6.

[50] Poindexter BB, Ehrenkranz RA, Stoll BJ, Wright LL, Poole WK, Oh W, et al. Parenteral glutamine supplementation does not reduce the risk of mortality or late-onset sepsis in extremely low birth weight infants. Pediatrics 2004 May;113(5):1209-15.

[51] Grover Z, Tubman R, McGuire W. Glutamine supplementation for young infants with severe gastrointestinal disease. Cochrane Database Syst Rev 2007; (1):CD005947.

[52] Albers MJ, Steyerberg EW, Hazebroek FW, Mourik M, Borsboom GJ, Rietveld T, et al. Glutamine supplementation of parenteral nutrition does not improve intestinal permeability, nitrogen balance, or outcome in newborns and infants undergoing digestive-tract surgery: results from a double-blind, randomized, controlled trial. Ann Surg 2005 Apr;241(4):599-606.

[53] Gore DC, Jahoor F. Deficiency in peripheral glutamine production in pediatric patients with burns. J Burn Care Rehabil 2000 Mar-Apr;21(2):2-7. 171; discussion.

[54] Wischmeyer PE, Lynch J, Liedel J, Wolfson R, Riehm J, Gottlieb L, et al. Glutamine administration reduces Gram-negative bacteremia in severely burned patients: a prospective, randomized, double-blind trial versus isonitrogenous control. Crit Care Med 2001 Nov;29(11):2075-80.

[55] Williams EA, Elia M, Lunn PG. A double-blind, placebo-controlled, glutaminesupplementation trial in growth-faltering Gambian infants. Am J Clin Nutr 2007 Aug;86(2):421-7. 
[56] Lima NL, Soares AM, Mota RM, Monteiro HS, Guerrant RL, Lima AA. Wasting and intestinal barrier function in children taking alanyl-glutamine-supplemented enteral formula. J Pediatr Gastroenterol Nutr 2007 Mar;44(3):365-74.

[57] Lima AA, Brito LF, Ribeiro HB, Martins MC, Lustosa AP, Rocha EM, et al. Intestinal barrier function and weight gain in malnourished children taking glutamine supplemented enteral formula. J Pediatr Gastroenterol Nutr 2005 Jan;40(1):28-35.

[58] Oudemans-van Straaten HM, Bosman RJ, Treskes M, van der Spoel H] Zandstra DF. Plasma glutamine depletion and patient outcome in acute ICU admissions. Intensive Care Med 2001 Jan;27(1):84-90.

[59] Heyland D, Muscedere J, Wischmeyer PE, Cook D, Jones G, Albert M, et al. A randomized trial of glutamine and antioxidants in critically ill patients. N Engl J Med 2013 Apr 18;368(16):1489-97.

[60] Rodas PC, Rooyackers O, Hebert C, Norberg A, Wernerman J. Glutamine and glutathione at ICU admission in relation to outcome. Clin Sci (Lond) 2012 Jun;122(12):591-7.
[61] Krajcova A, Ziak J, Jiroutkova K, Patkova J, Elkalaf M, Dzupa V, et al. Normalizing glutamine concentration causes mitochondrial uncoupling in an in vitro model of human skeletal muscle. JPEN J Parenter Enter Nutr 2013 Nov 29 [Epub ahead of print].

[62] Griffiths RD. Outcome of critically ill patients after supplementation with glutamine. Nutrition 1997 Jul-Aug;13(7-8):752-4.

[63] Glauser MP, Zanetti G, Baumgartner JD, Cohen J. Septic shock: pathogenesis. Lancet 1991 Sep 21;338(8769):732-6.

[64] Heyland DK, Dhaliwal R. Role of glutamine supplementation in critical illness given the results of the REDOXS study. JPEN J Parenter Enter Nutr $2013 ; 37(4): 442-3$

[65] Wischmeyer PE, Dhaliwal R, McCall M, Ziegler TR, Heyland DK. Parenteral glutamine supplementation in critical illness: a systematic review. Crit Care 2014 Apr 18;18(2):R76. 